CLINICAL STUDY

\title{
Muscle function and quality of life are not impaired in familial hypocalciuric hypercalcemia: a cross-sectional study on physiological effects of inactivating variants in the calcium-sensing receptor gene (CASR)
}

\author{
Niels Frederik Breum Jakobsen ${ }^{1}$, Lars Rolighed ${ }^{2}$, Peter H Nissen ${ }^{3}$, Leif Mosekilde ${ }^{1}$ and Lars Rejnmark ${ }^{1}$ \\ Departments of ${ }^{1}$ Endocrinology and Internal Medicine (MEA), ${ }^{2}$ Surgery P and ${ }^{3}$ Clinical Biochemistry, Aarhus University Hospital, \\ Tage-Hansens Gade 2, 8000 Aarhus C, Denmark
}

(Correspondence should be addressed to N F B Jakobsen; Email: fbjakobsen@gmail.com)

\begin{abstract}
Background: Familial hypocalciuric hypercalcemia (FHH) is often due to inactivating variants in the calcium-sensing receptor (CASR) gene causing chronically elevated plasma calcium levels with inappropriately normal or elevated parathyroid hormone levels. In patients with primary hyperparathyroidism, the state of hyperparathyroid hypercalcemia is associated with reduced muscle strength and impaired quality of life (QoL).

Objective: To study whether FHH affects muscle function, postural stability, and QoL.

Design: In a cross-sectional study, we investigated muscle strength (handgrip, elbow flexion/extension, and knee flexion/extension), balance function, physical activity, and QoL in 50 patients with FHH and in a similar number of age- and gender-matched population-based healthy controls. All but one of the FHH cases had genetically verified inactivating variants in the CASR gene.

Results: Studied subjects ( $n=100,68 \%$ females) had a mean age of 56.0 years. Muscle strength as assessed by measuring maximum force and maximum force production did not differ between the groups. Neither did groups differ in terms of QoL, physical activity, or postural stability, as assessed during normal standing with eyes open, normal standing with eyes closed, semi-tandem standing, or tandem standing. Adjustment for vitamin D status (plasma 25-hydroxyvitamin D levels) and BMI did not change results.

Conclusion: Despite a state of chronic hypercalcemia, muscle strength, balance function, and QoL are not impaired in patients with FHH. Our findings are reassuring for patients with FHH as they should not be considered as having a severe disease.
\end{abstract}

European Journal of Endocrinology 169 349-357

\section{Introduction}

The calcium-sensing receptor (CaSR) was first described by Brown et al. (1) in 1993. Today, the receptor is known to be expressed by cells of many different tissues including the parathyroid glands, bone, kidney, and skeletal muscles (2). Its major function is to sense small changes in plasma ionized calcium $\left(\mathrm{Ca}^{2+}\right)$ concentration and to couple this information to intracellular signaling pathways that modify parathyroid hormone (PTH) secretion and renal cation handling $(3,4)$. Lossof-function variants in the gene encoding the CASR on chromosome $3 \mathrm{q}$ are known to cause familial hypocalciuric hypercalcemia (FHH) type 1 (OMIN \#145980). The condition is inherited in an autosomal dominant manner and causes an increase in the set point of the parathyroid glands, i.e. the plasma $\mathrm{Ca}^{2+}$ concentration at which PTH secretion is half-maximal $(3,5)$.
Accordingly, higher than normal plasma $\mathrm{Ca}^{2+}$ levels are necessary to inhibit the release of PTH, resulting in hypercalcemia associated with inappropriately normal or elevated plasma levels of PTH (hyperparathyroid hypercalcemia) (4). The degree of hypercalcemia depends on how severely the variant affects the function of CaSR (6). Similarly, in the renal tubules, calcium reabsorption is increased causing a relatively low renal calcium excretion $(7,8,9)$. Recently, similar phenotypes have been shown to be attributable to mutations in the G protein alpha $11(G \alpha 11(G N A 11))$ gene (FHH type 2) and adaptor protein 2 sigma 1 (AP2S1) gene (FHH type 3) with loci placed on chromosomes 19p and 19q respectively (10). In rare cases, antibodies to the CaSR may also cause a FHH-like phenotype $(11,12)$.

$\mathrm{FHH}$ is easily misinterpreted with milder cases of primary hyperparathyroidism (PHPT), which is usually treated by parathyroidectomy (PTX). However, in the 


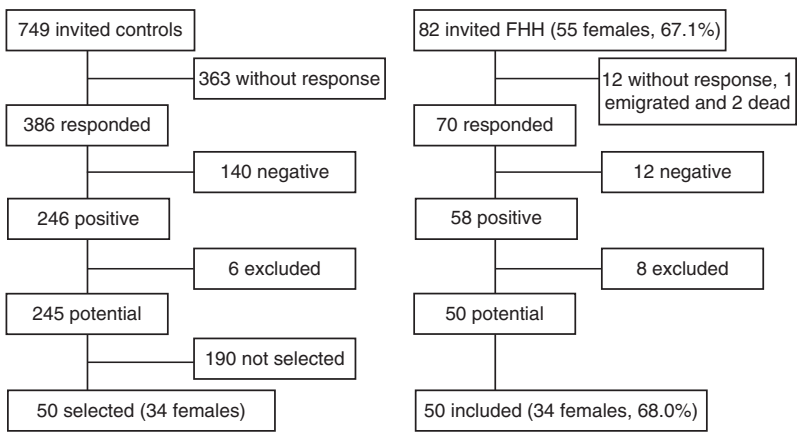

Figure 1 Study profile.

case of FHH, PTX is not only unnecessary but also inappropriate, as it does not cure FHH-associated hypercalcemia $(3,9)$. When FHH is not considered as an alternative diagnosis, failed PTX may lead to a suspicion of persistent PHPT with the risk of subsequent neck explorations, postoperative hypoparathyroidism, and recurrent laryngeal nerve palsy. Untreated PHPT is associated with an increased risk of renal calcifications, skeletal complications, and neuropsychological symptoms with a reduced quality of life (QoL) $(13,14$, $15,16,17)$. In addition, muscle strength and function is impaired in patients with PHPT but may improve following curative surgery $(18,19)$. Whether the symptoms of PHPT are due to hypercalcemia, high PTH levels, or concomitantly low vitamin D levels has not yet been resolved $(20,21,22,23)$. In contrast to PHPT, FHH is generally considered as an asymptomatic condition $(24,25)$. However, except for studies on skeletal effects, detailed investigations on possible physiological consequences of FHH are lacking (24). If hypercalcemia or elevated PTH levels cause a reduced muscular performance and/or an impaired well-being, patients with FHH may not be aware of this as the condition has been present throughout their life.

The aim of this study was to investigate whether FHH is associated with impaired muscle function and QoL compared with age- and sex-matched populationbased healthy individuals.

\section{Subjects and methods}

\section{Design and participants}

In a cross-sectional study, we compared 50 patients diagnosed with FHH with 50 sex- and aged-matched population-based controls. Exclusion criteria for both patients and controls were pregnancy, major medical or social problems suspected to influence study outcome including impaired renal function (plasma creatinine $>125 \mu \mathrm{mol} / \mathrm{l}$ ), malignancies diagnosed within the last 5 years or still requiring treatment (except for treated non-melanoma skin cancer or treated carcinoma in situ with more than 2 years since last therapy), untreated intestinal malabsorption, liver disease, active pancreatitis, or chronic drug or alcohol abuse. In addition, we excluded subjects on treatment with drugs that may affect the function of CaSR (lithium, strontium, and cinacalcet). Controls with known diseases in bone/ calcium homeostasis (except osteoporosis) were also excluded. The study profile is shown in Fig. 1 .

\section{Recruitment of patients and controls}

At our university Department of Endocrinology, we had information on 82 patients with FHH. Sixty-six patients had participated in previous studies from our group (21) whereas 16 patients were identified from subsequent family studies or they were new referrals. All except one patient had a genetically verified diagnosis (Fig. 2). In one patient, gene analysis only showed a p.R990G variant in the CASR gene, which is now considered as a common variant not associated with FHH $(6,26)$. However, as the patient had hypercalcemia with elevated PTH levels and a low calcium:creatinine clearance ratio (CCCR) as well as an offspring with hypercalcemia, this patient was considered as having FHH. The patient has not yet been studied for variants in other possible genes. Of the identified 82 patients, two had died and one had immigrated leaving 79 potential patients for the study of whom 26 were index patients. The gene variants present in this study are summarized in Table 1. Potential participants were invited by letter with a reminder to non-responders $(n=17)$. Among 70 responders, 58 accepted to participate. Subsequently, two were excluded because of pregnancy, three because

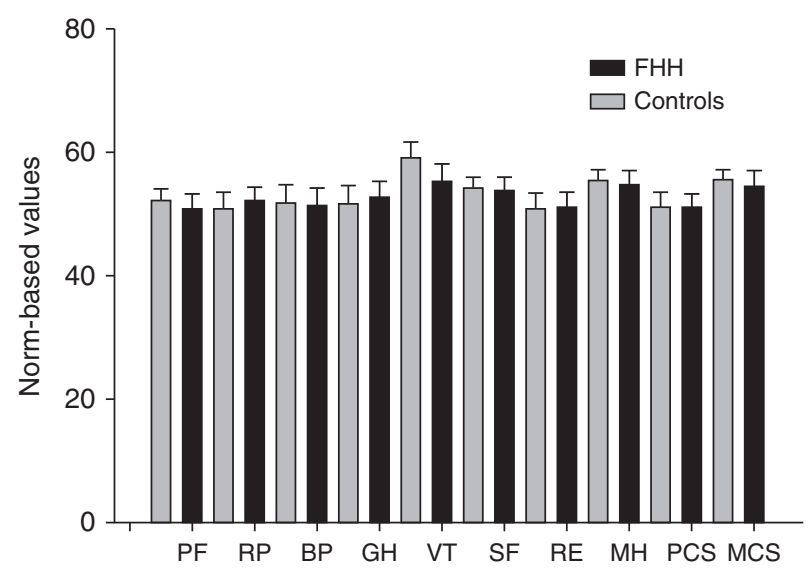

Figure 2 QoL according to the Short Form 36 Health Survey version 2 (SF36v2) questionnaire in patients with familial hypocalciuric hypercalcemia $(\mathrm{FHH})$ and matched controls. The questionnaire is composed of 36 questions grouped into eight health concepts, i.e. physical functioning (PF), role limitations due to physical problems $(\mathrm{RP})$, bodily pain (BP), general health $(\mathrm{GH})$, vitality (VT), social functioning (SF), role limitations due to emotional problems (RE), and mental health (MH), which together form a mental component summary score and a physical component summary score. None of the measured indices differed $(P>0.05)$ between groups. 
Table 1 Variants of the CASR gene present in the study.

\begin{tabular}{llr}
\hline Nucleotide variant & Predicted amino acid & $\boldsymbol{n}$ \\
\hline c.1189G $>$ A & p.G397R & 5 \\
c.1525G $>$ A & p.G509R & 5 \\
c.1657G $>$ A & p.G553R & 2 \\
c.1719T $>$ A & p.Y573X & 2 \\
c.1745G $>$ A & p.C582F & 2 \\
c.1745G $>$ T & p.C582Y & 4 \\
c.1868G $>$ A & p.G623D & 2 \\
c.1997-1998 insT & p.L666fSX707 \\
c.2008G $>$ A & p.G670R & 2 \\
c.2182G $>$ T & p.V728F & 1 \\
c.2224T $>$ C & p.W742R & 6 \\
c.2383-2384delC & p.R795fsX836 & 1 \\
c.2656C $>$ T & p.R886W & 2 \\
c.512G $>$ A & p.S171N & 11 \\
c.662C $>$ A & p.P221Q & 3 \\
\hline
\end{tabular}

of cancers, two because of chronic disabling diseases, and one due to treatment with lithium.

We recruited controls through direct mailings to a random sample from the general background population, i.e. using the Danish Civil Registration System, a random list of males and females living in the area of our University Hospital was retrieved. For each participant with $\mathrm{FHH}$, an invitation letter was sent to 5-10 age ( \pm 2 years)- and gender-matched controls. Among 749 invited controls, 246 accepted. Subsequently, six were excluded and 50 were randomly selected to be age and sex matched with cases (Fig. 1). All participants gave verbal and written informed consent. The study was conducted according to the Declaration of Helsinki II. The study was approved by The Central Denmark Region Committees on Health Research Ethics (\#M-2010-0296) and notified to The Danish Data Protection Agency (\#2011-41-5733).

\section{Biochemistry}

We drew fasting blood samples after $1 \mathrm{~h}$ of bed rest. In addition, participants collected a 24-h urine sample. Samples were analyzed or frozen immediately at $-80{ }^{\circ} \mathrm{C}$ until analyses.

Plasma levels of calcium and creatinine were determined by standard laboratory methods using Roche/Hitachi Cobas systems (Roche Diagnostics $\mathrm{GmbH})$. Creatine kinase (CK) was measured using a NADPH-generated catalytic reaction on an automated instrument (Cobas 6000, Roche Diagnostics $\mathrm{GmbH}$ ). Plasma levels of 25-hydroxyvitamin D (250HD) were analyzed by isotope dilution liquid chromatographytandem mass spectrometry $(27,28)$. This method quantifies both $250 \mathrm{HD} 2$ and 250HD3 and total 250HD. Calibrators traceable to NIST SRM 972 (Chromsystems, Münich, Germany) were used. Coefficient of variance $(\mathrm{CV})$ values for $25(\mathrm{OH}) \mathrm{D} 3$ were 6.4 and $9.1 \%$ at levels of 66.5 and $21.1 \mathrm{nmol} / \mathrm{l}$, and for
$25(\mathrm{OH}) \mathrm{D} 2$, the $\mathrm{CV}$ values were 8.8 and $9.4 \%$ at levels of 41.2 and $25.3 \mathrm{nmol} / \mathrm{l}$ respectively. We measured plasma intact PTH using a second-generation electrochemiluminescent immunoassay on an automated instrument (Cobas 6000, Roche Diagnostics $\mathrm{GmbH}$ ). The lower limit of detection of the assay is $0.127 \mathrm{pmol} / \mathrm{l}$, with a total imprecision of 3.3 and $2.7 \%$ at PTH levels of 3.7 and $26.6 \mathrm{pmol} / \mathrm{l}$ respectively. Plasma CCCR was calculated as (24-h urinary calcium/plasma calcium $) /(24-\mathrm{h}$ urinary creatinine/plasma creatinine).

\section{Genetics}

FHH patients were characterized by molecular genetic analysis of the CASR gene as described previously $(6,29)$. Sequences were aligned to GenBank reference sequence NM_000388.2. Findings were confirmed in a second analysis on separately drawn blood. The nomenclature of the sequence variants follows the current guidelines (30).

\section{Muscle and balance function tests}

We measured the maximal isometric muscle strength as maximal force in Newton $(N)$ and maximal force production in Newton per second $(\mathrm{N} / \mathrm{s})$ of handgrip, elbow extension/flexion, and knee extension/flexion at the dominant hand side using an adjustable dynamometer chair (Good Strength, Metitur Ltd., Helsinki, Finland) (31). Handgrip strength was measured by a dynamometer handle fixed to the arm of the chair. Elbow extension and flexion strengths were measured with the elbow in a neutral position at an angle of $90^{\circ}$ and with the forearm supported and the wrist attached by a belt to the dynamometer. Knee extension and flexion strengths were measured at an angle of $60^{\circ}$ and $90^{\circ}$ from the fully extended leg toward flexion. The ankle was fastened $5 \mathrm{~cm}$ above the lateral malleolus by a belt to the dynamometer and the thigh supported with another belt. The trunk was fastened with three belts to avoid transferring strength from other muscles to the measurements. We repeated the exercises three times with an inter-trial rest of $30 \mathrm{~s}$. The best of the three results was used.

We assessed balance function in terms of postural stability using an equilateral triangular force platform connected to a stadiometer (Good Balance, Metitur Ltd.) (32). The platform is divided into a coordinate system with medial-lateral and anterior-posterior axes. The platform generates a center of pressure from a person, and any movements or sway will result in changes along the axes. These changes are expressed as velocity moment $\left(\mathrm{mm}^{2} / \mathrm{s}\right)$, which gives an evaluation of the postural stability, i.e. the smaller the velocity moment, the better the postural stability. The effect of body height and vertical location of the center of body mass were adjusted for by the formula: (velocity moment/(height in $\left.\mathrm{cm})^{2}\right) \times 180^{2}$. The measurements were performed 
during four different exercises with the participants standing on the platform with arms along the side: i) normal standing with $20 \mathrm{~cm}$ space between the feet and eyes open; ii) similar, but with eyes closed; iii) semitandem position with the heel of the first foot on the side of the first toe on the second foot; and iv) tandem position with the first toe on the back foot touching the heel of the fore foot. In this way, the test was started with the easiest and then advancing to more difficult exercise. Each trial of 20s was repeated three times, and the best result was used for analyses.

Physical function was further evaluated using two simple tests combining physical strength, balance, and coordination. Using the Timed Up and Go (TUG) test, we measured the time a subject used to stand up from sitting in a chair, walk $3 \mathrm{~m}$, turn around, walk back, and sit down. The subjects were not allowed to use their arms when raising form the chair $(33,34)$. In Repeated Chair Stands (RCS) test, we measured the time for ten consecutive repeated chair raises without use of arms. Participants were encouraged to perform the task as quickly as possible. In both tests, the fastest time (best performance) of two trials was used for analysis $(33,35)$.

\section{Questionnaires}

We assessed physical activity using a validated physical activity scale (PAS) questionnaire consisting of nine activity categories with increasing intensity (36). Each category represents a defined value expressed in metabolic equivalents (METs). The participants filled in how much time they used according to each category on an average day. By adding the METs from the different categories of activities, the total amount of physical activity was estimated. We stratified data between workers and non-workers. Non-workers included participants who are retired, unemployed, and students.

We assessed QoL using the Short Form 36 Health Survey version 2 (SF36v2), a highly validated questionnaire consisting of 36 questions grouped into eight health concepts (physical functioning, role limitation caused by physical problems, bodily pain, general health perception, vitality, social functioning, role limitation caused by emotional problems, and mental health), which together form a mental component summary (MCS) score and physical component summary (PCS) score. The scores were calculated to norm-based values $(17,37)$. In addition, we assessed well-being of our participants using the WHO-5-Well-Being-index (WHO-5), which is a short screening questionnaire for the detection of depression with five questions with six answer options for each question. According to the answers, a summary score is calculated in which 0 is worst thinkable wellbeing and 100 is best thinkable well-being $(17,38)$.

Using interviews and a general questionnaire, we collected information on participants' health and lifestyle habits in terms of known disease, drug treatment, daily intake of dairy products, smoking habits, alcohol intake, use of vitamin supplements, and for women menopausal status. Daily dietary calcium intake was estimated as $(350+(150 \times$ 'glasses of milk' $)+(200 \times$ 'slices of bread with cheese' $)+(250 \times$ 'dairy product servings') $)$ (39). Scale body weight was measured in light indoor clothes and height was measured without shoes using a stadiometer. BMI was calculated as weight $(\mathrm{kg})$ divided by the square of height $(\mathrm{m})$.

\section{Statistical analysis}

Prior to study, we performed sample size calculations showing that 25-30 participants were needed to be included in each group in order to show a mean difference between groups of 40Newton in leg strength $(\beta=0.20, \alpha=0.05)$. We assessed differences between groups using $\chi^{2}$ test for categorical variables. For continuous variables, we tested differences between groups using a two-sample $t$-test or Mann-Whitney $U$ test, as appropriate according to the distribution of data. Correlations were assessed by Pearson's or Spearman's correlation coefficients, as appropriate. We used a general linear regression model to adjust for differences between groups. Results are reported as mean \pm s.D. or as median with interquartile (25 and $75 \%$ percentiles) ranges, as appropriate according to the distribution of data. A $P$ value $<0.05$ was considered statistically significant. We used IBM SPSS Statistics version 20 (IBM) for statistical analyses.

\section{Results}

Characteristics of included participants are shown in Table 2. Our participants had a mean age of 56 (range 18-85) years and $68 \%$ were females. Patients and controls were comparable regarding height, weight, BMI, smoking, use of drugs, and use of vitamin D supplements. Use of calcium supplement was more common among controls than in the $\mathrm{FHH}$ group $(P=0.05)$, but total intake of calcium did not differ between groups (Table 2).

As expected, FHH patients had significantly higher plasma levels of ionized calcium $(P<0.01)$ and PTH $(P=0.02)$ than controls, whereas CCCR was lower in FHH than in controls $(P<0.01)$. Creatinine clearance and plasma levels of creatinine, CK, and 250HD did not differ between groups (Table 2).

\section{Muscle and balance function}

The proportion of participants who reported a feeling of muscle fatigue or difficulties in climbing stairs or rising from a chair without support did not differ between patients with FHH and the controls (Table 2). Maximum muscle strength as assessed by measuring maximum force and maximum force production at the seven different muscle groups/positions did not differ 
Table 2 Characteristics of patients with familial hypocalciuric hypercalcemia $(\mathrm{FHH})$ and their matched controls. Number $(n)$ with percentages (\%), mean \pm s.D., or median with interquartile (25 and $75 \%$ percentiles) range.

\begin{tabular}{|c|c|c|c|}
\hline Variable & Controls & FHH & $P$ value \\
\hline Number $(n)$ & 50 & 50 & \\
\hline Age (range) & $56(23-82)$ & $56(23-82)$ & - \\
\hline \multicolumn{4}{|l|}{ Gender } \\
\hline \multicolumn{4}{|l|}{ Female } \\
\hline$n(\%)$ & $34(68.0 \%)$ & $34(68.0 \%)$ & - \\
\hline Age (years) & $57.4(15.7)$ & $57.4(15.7)$ & - \\
\hline \multicolumn{4}{|l|}{ Male } \\
\hline$n(\%)$ & $16(32.0 \%)$ & $16(32.0 \%)$ & - \\
\hline Age (years) & $52.5(15.8)$ & $52.5(15.8)$ & - \\
\hline \multicolumn{4}{|l|}{ Anthropometrics } \\
\hline Height $(\mathrm{cm})$ & $170.1(8.4)$ & $168.7(8.6)$ & 0.43 \\
\hline Weight $(\mathrm{kg})$ & $77.1(14.2)$ & 75.7 (16.7) & 0.66 \\
\hline $\operatorname{BMI}\left(\mathrm{kg} / \mathrm{m}^{2}\right)$ & $26.6(4.5)$ & $26.4(4.7)$ & 0.83 \\
\hline Use of drugs (\%) & $27(54.0)$ & $28(56.0)$ & 0.69 \\
\hline Antihypertensive drugs ( $n(\%)$ ) & $17(34.0)$ & $16(32.0)$ & $>0.99$ \\
\hline Cholesterol-lowering drugs $(n(\%))$ & $8(15.7)$ & $11(21.6)$ & 0.45 \\
\hline Anti-osteoporotic drugs $(n(\%))$ & $4(7.8)$ & $4(7.8)$ & $>0.99$ \\
\hline \multicolumn{4}{|l|}{ Calcium and vitamin D intake } \\
\hline Use of vitamin D supplements $(n(\%))$ & $34(68.0)$ & $28(56.0)$ & 0.32 \\
\hline Vitamin D intake from supplement ( $\mu \mathrm{g} /$ day) & $8.8(0.0 ; 20.0)$ & $5.0(0.0 ; 24)$ & 0.53 \\
\hline User of calcium supplements $(n(\%))$ & $23(46.0)$ & $13(26.0)$ & 0.05 \\
\hline Calcium intake from supplements (mg/day) & $0(0 ; 400)$ & $0(0 ; 400)$ & 0.76 \\
\hline Dietary calcium intake (mg/day) & $1000(787 ; 1263)$ & $1000(750 ; 1250)$ & 0.87 \\
\hline Total calcium intake (mg/day) $)^{\mathrm{a}}$ & $1225(953 ; 1638)$ & $1050(763 ; 1575)$ & 0.35 \\
\hline \multicolumn{4}{|l|}{ Smoking (\%) } \\
\hline Former smoker & $24(48.0)$ & $19(38.0)$ & 0.47 \\
\hline Current smoker & $8(16.0)$ & $13(26.0)$ & 0.20 \\
\hline \multicolumn{4}{|l|}{ Self-reported muscle weakness (\%) } \\
\hline Feeling of muscle fatigue $(n(\%))$ & $9(18.0)$ & $8(16.0)$ & 0.86 \\
\hline Difficulties in climbing stairs without support & $9(18.0)$ & $5(10.0)$ & 0.28 \\
\hline Difficulties in rising from a chair without support & $8(16.0)$ & $3(6.0)$ & 0.13 \\
\hline \multicolumn{4}{|l|}{ Biochemistry } \\
\hline Calcium:creatinine clearance ratio (CCCR) & $0.011 \pm 0.005$ & $0.008 \pm 0.004$ & $<0.01$ \\
\hline lonized calcium (mmol/l) & $1.24 \pm 0.03$ & $1.45 \pm 0.12$ & $<0.01$ \\
\hline Creatine kinase (CK; U/I) & $83(63 ; 132)$ & $68(4 \overline{9} ; 103)$ & 0.09 \\
\hline Creatinine clearance $(\mathrm{ml} / \mathrm{min})$ & $124 \pm 39$ & $118 \pm 32$ & 0.39 \\
\hline $25 \mathrm{OHD}(\mathrm{nmol} / \mathrm{l})$ & $51 \pm 25$ & $51 \pm 21$ & 0.97 \\
\hline $\mathrm{PTH}(\mathrm{pmol} / \mathrm{l})$ & $3.9(3.2 ; 4.8)$ & $4.7(3.7 ; 6.4)$ & 0.02 \\
\hline
\end{tabular}

${ }^{a}$ Dietary calcium plus calcium intake from supplement $(\mathrm{mg} /$ day $)$.

significantly between FHH cases and controls (Table 3). Stratification by sex showed, however, a higher maximal force at knee flexion $60^{\circ} \mathrm{s}(P=0.02)$ in male FHH patients compared with their matched controls (Table 3), but this was not significant after adjusting for BMI and plasma 250HD levels $(P=0.06)$.

Overall, plasma $\mathrm{Ca}^{2+}$ did not correlate with maximum force or maximum force production in any of the investigated muscle groups and this was not changed by adjusting for age, sex, and BMI. Plasma PTH levels correlated borderline significantly with muscle force at knee flexion $60^{\circ} \mathrm{s}(r=0.19 P=0.06)$, but not at any of the other investigated muscle groups. The association became significant after adjustments for age, sex, and BMI $(r p=0.29, P=0.005)$. In bivariate correlation analyses, plasma PTH levels did not correlate with maximum force production at any of the muscle groups. However, after adjusting for age, sex, and BMI, plasma PTH levels correlated inversely with elbow flexion $(r p=-0.152, P<0.05)$, knee flexion $90^{\circ} \mathrm{s}(r p=-0.141, P<0.05)$, and knee extension $90^{\circ} \mathrm{s}$ $(r p=-0.112, P<0.01)$ (Table 4).

Overall or stratified by sex, postural stability did not differ between FHH patients and controls (Table 5). Adjustment for plasma 250HD, PTH, and BMI made no differences (data not shown). In normal standing with closed eyes, plasma PTH correlated with velocity moment $(r p=0.21, P=0.034)$ but neither plasma $\mathrm{Ca}^{2+}$ nor plasma PTH correlated with postural stability at any of the other positions even after adjustments for age, sex, and BMI. There were no differences between groups in the TUG test or the RCS test. Stratification by gender or adjustment for PTH, BMI or 250HD did not change the results (data not shown).

\section{Physical activity}

The PAS showed no significant differences between groups. Stratification by working status did not change the results (data not shown). 
Table 3 Maximum force and maximum force production. Median with interquartile (25 and $75 \%$ percentiles) range.

\begin{tabular}{|c|c|c|c|c|c|c|}
\hline \multirow[b]{2}{*}{ Variables } & \multicolumn{3}{|c|}{ Maximum force $(N)$} & \multicolumn{3}{|c|}{ Maximum force production $(\mathrm{N} / \mathrm{s})$} \\
\hline & Control & $\mathrm{FHH}$ & $P$ value & Control & $\mathrm{FHH}$ & $P$ value \\
\hline All cases $(n)$ & 50 & 50 & & 50 & 50 & \\
\hline Handgrip & $369(286 ; 511)$ & $363(299 ; 606)$ & 0.84 & $1739(1111 ; 2584)$ & $1801(1174 ; 2702)$ & $>0.99$ \\
\hline Elbow flexion & $221(188 ; 288)$ & $217(189 ; 301)$ & 0.93 & $1016(695 ; 1763)$ & $958(637 ; 1499)$ & 0.65 \\
\hline Elbow extension & $168(132 ; 221)$ & $160(126 ; 230)$ & 0.85 & $762(453 ; 1195)$ & $594(436 ; 886)$ & 0.27 \\
\hline Knee flexion $60^{\circ}$ & $215(148 ; 271)$ & $212(160 ; 298)$ & 0.57 & $627(263 ; 891)$ & 537 (383; 929) & 0.79 \\
\hline Knee flexion $90^{\circ}$ & 209 (163; 270) & $202(149 ; 285)$ & 0.95 & $800(412 ; 1071)$ & $709(417 ; 1011)$ & 0.46 \\
\hline Knee extension $60^{\circ}$ & $462(332 ; 574)$ & $482(369 ; 681)$ & 0.30 & $1811(1109 ; 2594)$ & 1954 (1212; 2754) & 0.78 \\
\hline Knee extension $90^{\circ}$ & $451(326 ; 559)$ & $426(339 ; 598)$ & 0.68 & $1562(1104 ; 2383)$ & 1763 (1226; 2333) & 0.69 \\
\hline Male $(n)$ & 16 & 16 & & 16 & 16 & \\
\hline Handgrip & $640(475 ; 689)$ & $679(597 ; 791)$ & 0.54 & $2922(2136 ; 3152)$ & 2984 (2029; 3566) & 0.81 \\
\hline Elbow flexion & $329(278 ; 380)$ & $378(308 ; 389)$ & 0.72 & 2098 (1130; 2328) & $2036(1284 ; 2658)$ & 0.75 \\
\hline Elbow extension & $234(215 ; 251)$ & $240(216 ; 263)$ & 0.62 & $1016(824 ; 1715)$ & $1054(798 ; 1636)$ & 0.81 \\
\hline Knee flexion $60^{\circ}$ & $284(239 ; 348)$ & $365(285 ; 417)$ & 0.02 & $939(651 ; 1207)$ & $1006(805 ; 1540)$ & 0.34 \\
\hline Knee flexion $90^{\circ}$ & $297(220 ; 336)$ & $311(266 ; 366)$ & 0.81 & $1178(881 ; 1437)$ & $1068(845 ; 1514)$ & 0.78 \\
\hline Knee extension $60^{\circ}$ & $633(492 ; 816)$ & $697(593 ; 832)$ & 0.54 & $2596(1811 ; 3621)$ & 3037 (1662; 4026) & 0.87 \\
\hline Knee extension $90^{\circ}$ & $580(501 ; 708)$ & $689(502 ; 775)$ & 0.59 & 2529 (1868; 3449) & $2333(1878 ; 3331)$ & 0.59 \\
\hline Female $(n)$ & 34 & 34 & & 34 & 34 & \\
\hline Handgrip & $318(263 ; 385)$ & $315(284 ; 372)$ & 0.76 & $1485(838 ; 2021)$ & $1466(1111 ; 1830)$ & 0.99 \\
\hline Elbow flexion & $206(175 ; 227)$ & $199(179 ; 223)$ & 0.58 & $862(637 ; 1188)$ & $776(450 ; 1140)$ & 0.32 \\
\hline Elbow extension & $148(112 ; 170)$ & $145(122 ; 166)$ & 0.82 & $527(364 ; 915)$ & $489(374 ; 776)$ & 0.27 \\
\hline Knee flexion $60^{\circ}$ & $165(136 ; 234)$ & $184(141 ; 227)$ & 0.70 & $460(225 ; 766)$ & $469(268 ; 584)$ & 0.50 \\
\hline Knee flexion $90^{\circ}$ & $187(132 ; 220)$ & $192(142 ; 221)$ & 0.92 & 661 (326; 972) & $565(374 ; 834)$ & 0.54 \\
\hline Knee extension $60^{\circ}$ & 351 (289; 499) & $434(319 ; 521)$ & 0.33 & $1226(977 ; 2103)$ & $1744(1140 ; 2280)$ & 0.93 \\
\hline Knee extension $90^{\circ}$ & $376(303 ; 468)$ & $373(324 ; 471)$ & 0.59 & $1217(924 ; 1954)$ & $1495(1006 ; 2108)$ & 0.37 \\
\hline
\end{tabular}

\section{Quality of life}

As shown in Fig. 2, QoL as assessed by the SF36v2- and WHO-5 index questionnaires did not differ significantly between FHH patients and their matched controls, except that the vitality score was borderline significantly lower in the FHH patients $(P=0.08)$. However, mental and PCSs did not differ between groups.

\section{Discussion}

In a cross-sectional study, we found no evidence to support that FHH is associated with decreased muscle function, an impaired postural stability, or a reduced QoL despite chronically elevated plasma levels of $\mathrm{Ca}^{2+}$ and PTH. Accordingly, in contrast to patients with hypercalcemic hyperparathyroidism due to PHPT, mildly elevated plasma levels of calcium and PTH do not seem to compromise physiological functions in patients with FHH.

Our findings are in contrast to the study by Law et al. (24), suggesting that FHH patients may have some muscle weakness and lack of pep and energy. In this study, we rather found an opposite tendency. We investigated muscle function as objectively as possible, and when asking directly for muscle weakness, the proportion of FHH patients reporting such symptoms did not differ from the proportion in the group of controls. The activity scale used by us is well validated (36) and may be a better tool to assess activity than a few simple questions on muscle weakness and sense of pep and energy as used in the study by Law et al. (24).

Skeletal muscle expresses the CaSR (40) as well as receptors for PTH (41) and vitamin D (42). The precise function of the CaSR in skeletal muscle cells has not yet been elucidated. However, in patients with $\mathrm{FHH}$, the CaSR function is probably impaired in all tissues, including muscles. Accordingly, the post-receptor signaling in muscles may be normal despite elevated plasma $\mathrm{Ca}^{2+}$ levels. Nevertheless, it seems likely that the abnormal high extracellular $\mathrm{Ca}^{2+}$ concentration in FHH may affect physiological processes directly through an altered chemical or electrophysiological gradient. The lack of effects of hypercalcemia in FHH on muscle performance in this study suggests, however, that these mechanisms are of limited influence. In contrast, hyperparathyroid hypercalcemia in patients with

Table 4 Multiple regression analyses on the effects of plasma levels of ionized calcium and PTH on muscle strength as assessed by measuring maximal force production. Adjusted for age, sex, and BMI. Partial regression coefficients $(r p)$.

\begin{tabular}{lcc}
\hline Variable & $\begin{array}{c}\text { Ionized calcium, } \boldsymbol{r p} \\
(P \text { value })\end{array}$ & $\begin{array}{c}\text { PTH, } \boldsymbol{r p} \\
(P \text { value })\end{array}$ \\
\hline Handgrip & $-0.056(0.52)$ & $-0.099(0.11)$ \\
Elbow flexion & $-0.137(0.07)$ & $-0.152(<0.05)$ \\
Elbow extension & $-0.148(0.07)$ & $-0.084(0.35)$ \\
Knee flexion $60^{\circ}$ & $-0.061(0.48)$ & $0.050(0.84)$ \\
Knee flexion $90^{\circ}$ & $-0.151(0.07)$ & $-0.141(<0.05)$ \\
Knee extension $60^{\circ}$ & $-0.043(0.48)$ & $-0.079(0.10)$ \\
Knee extension $90^{\circ}$ & $-0.070(0.25)$ & $-0.112(<0.01)$ \\
\hline
\end{tabular}


Table 5 Balance measurement. Median with interquartile (25 and $75 \%$ percentiles) range.

\begin{tabular}{|c|c|c|c|}
\hline \multirow{2}{*}{$\frac{\text { Variable }}{\text { Position }}$} & \multicolumn{3}{|c|}{ Postural stability $\left(\mathrm{mm}^{2} / \mathrm{s}\right)$} \\
\hline & Control $(n=50)$ & $\mathrm{FHH}(n=50)$ & $P$ value \\
\hline $\begin{array}{l}\text { Normal stand- } \\
\text { ing, EO }\end{array}$ & $3.7(2.4 ; 6.2)$ & $3.5(2.4 ; 5.2)$ & 0.44 \\
\hline Male & $3.3(2.2 ; 4.9)$ & $3.9(2.8 ; 5.5)$ & 0.49 \\
\hline Female & $4.2(2.4 ; 6.4)$ & $3.4(2.2 ; 5.2)$ & 0.16 \\
\hline $\begin{array}{l}\text { Normal stand- } \\
\text { ing, EC }\end{array}$ & $5.8(4.2 ; 10.4)$ & $7.7(4.5 ; 11.5)$ & 0.30 \\
\hline Male & $5.8(3.9 ; 10.8)$ & $9.6(6.9 ; 14.9)$ & 0.10 \\
\hline Female & $5.8(4.2 ; 10.0)$ & $6.4(3.2 ; 10.7)$ & 0.91 \\
\hline $\begin{array}{l}\text { Semi-tandem } \\
\text { standing, EO }\end{array}$ & $21.0(14.7 ; 31.2)$ & $22.6(15.6 ; 31.6)$ & 0.69 \\
\hline Male & $21.8(15.7 ; 34.2)$ & $20.7(13.7 ; 24.9)$ & 0.49 \\
\hline Female & $20.6(13.1 ; 31.2)$ & $24.6(16.8 ; 31.8)$ & 0.35 \\
\hline Tandem, EO & $38.1(23.9 ; 65.7)$ & $37.1(23.8 ; 60.2)$ & 0.95 \\
\hline Male & $31.3(21.7 ; 74.7)$ & $37.1(23.5 ; 62.9)$ & 0.93 \\
\hline Female & $39.3(25.3 ; 61.5)$ & $38.1(23.8 ; 60.2)$ & 0.86 \\
\hline
\end{tabular}

EO, eyes open; EC, eyes closed.

PHPT has been associated with muscular weakness in several studies, although the mechanism of action causing such symptoms is unknown $(16,18,43)$. Our findings may suggest that CaSR is involved in some of the adverse physiological effects of hypercalcemia. In patients with acquired hypercalcemia due to PHPT, the CaSR is not 'insensitive' to the hypercalcemia as in patients with $\mathrm{FHH}$. Accordingly, the muscle impairment and reduced QoL often encountered in patients with PHPT may (hypothetically) be due to an enhanced postreceptor signaling in affected tissues caused by the acquired state of hypercalcemia, whereas such adverse effects of hypercalcemia do not occur in patients with an inactivating mutation in the CASR gene. If so, it may be that elevated PTH levels are of minor importance to the symptomatology of PHPT. Whether intracellular calcium concentration differs between FHH and PHPT is currently unknown. Further studies including tissue biopsies are needed to clarify this.

Although it may seem that plasma PTH levels are of less importance than plasma calcium levels to muscle function, our findings do support an effect of PTH on muscle function and that PTH may affect muscle force $(N)$ and force production (N/s) differentially. Compared with their controls, male $\mathrm{FHH}$ patients had a borderline significantly better muscle force at knee flexion $60^{\circ} \mathrm{s}$, and in the entire group of studied subjects, muscle force at knee flexion $60^{\circ} \mathrm{s}$ correlated positively with plasma levels of PTH. On the contrary, plasma PTH levels were inversely associated with maximum force production in the entire group of studied subjects, after adjustment for age, sex, and BMI. Accordingly, PTH may improve muscle force, although it reduces the speed by which the force is attained. However, it should be noted that these findings were not present in all investigated muscle groups. Further studies should aim to assess whether PTH affects muscles in such a manner or whether our observations are random findings due to the large number of tests performed.

Further studies on patients with PHPT should also aim at investigating whether muscle weakness is caused by hypercalcemia per se or rather is attributable to elevated plasma PTH levels (23), vitamin D insufficiency (20), or an increased BMI (44). In our study, plasma 250HD levels and vitamin D intakes were similar in FHH cases and controls. We could therefore not explore the effects of altered vitamin D status on muscle function in our patients.

In addition to muscular impairment, QoL has been reported to be reduced in patients with PHPT but may improve following surgical cure (15). We did not find evidence of a reduced QoL in patients with FHH. Interestingly, in a previous study from our group, we investigated QoL in a group of patients with prior PHPT, who had been surgically cured $\sim 7$ years before the investigation (17). The former patients had an impaired QoL as assessed by the SF36v2 questionnaire compared with a group of age- and gender-matched controls, indicating that abolishment of hypercalcemia did not result in a full regain of QoL. In this study, lifelong hypercalcemia was not associated with an impaired QoL. Accordingly, further studies are needed to resolve whether mild-to-moderate hypercalcemia actually affects QoL.

\section{Strengths and limitations to study}

The major strength of this study is the uniform program of investigation applied to all participants according to a predefined protocol. Furthermore, FHH patients were well matched with controls recruited randomly from the general background population. In most cases, patients and controls were investigated within 3 weeks avoiding seasonal variations in $25 \mathrm{OHD}$. All investigations were carried out by trained personnel.

Regarding FHH patients, all except one had genetically verified variants in the CaSR explaining their hypercalcemia. The controls may contribute to some uncertainty because recruitment of healthy volunteers may involve selection bias, i.e. in the muscle investigations, there may be some potential inaccuracy caused by difference in motivation when measuring maximal strength. Using the best of three measurements, we aimed at reducing this bias.

In conclusion, inactivating variations in the CASR gene in patients with $\mathrm{FHH}$ are not associated with impaired muscle function or a reduced QoL as seen in patients with hyperparathyroid hypercalcemia due to PHPT. Our findings are reassuring for patients with FHH as they should not be considered as having a debilitating disease.

\section{Declaration of interest}

The authors declare that there is no conflict of interest that could be perceived as prejudicing the impartiality of the research reported. 


\section{Funding}

This work was supported by a grant (\#10-094047) from The Danish Council for independent Research in Medical Sciences (FSS).

\section{Acknowledgements}

The study was conducted at Osteoporosis Clinic, Tage-Hansens Gade, Aarhus University Hospital, and we hereby thank all the staff for support during the investigations.

\section{References}

1 Brown EM, Gamba G, Riccardi D, Lombardi M, Butters R, Kifor O, Sun A, Hediger MA, Lytton J \& Hebert SC. Cloning and characterization of an extracellular $\mathrm{Ca}(2+)$-sensing receptor from bovine parathyroid. Nature 1993366 575-580. (doi:10.1038/ 366575a0)

2 Ward BK, Magno AL, Walsh JP \& Ratajczak T. The role of the calcium-sensing receptor in human disease. Clinical Biochemistry 201245 943-953. (doi:10.1016/j.clinbiochem.2012.03.034)

3 Christensen SE, Nissen PH \& Schwarz P. Investigation and diagnosis of familial hypocalciuric hypercalcemia in Denmark. Ugeskrift for Laeger $2005 \mathbf{1 6 7}$ 905-910.

4 Brown EM \& MacLeod RJ. Extracellular calcium sensing and extracellular calcium signaling. Physiological Reviews 200181 239-297.

5 Tfelt-Hansen J \& Schwarz P. The human calcium-sensing receptor's role in illness and targets for therapy. Ugeskrift for Laeger 2003165 2283-2287.

6 Nissen PH, Christensen SE, Heickendorff L, Brixen K \& Mosekilde L. Molecular genetic analysis of the calcium sensing receptor gene in patients clinically suspected to have familial hypocalciuric hypercalcemia: phenotypic variation and mutation spectrum in a Danish population. Journal of Clinical Endocrinology and Metabolism 2007 92 4373-4379. (doi:10.1210/jc.2007-0322)

7 Christensen SE, Nissen PH, Vestergaard P \& Mosekilde L. Familial hypocalciuric hypercalcaemia: a review. Current Opinion in Endocrinology, Diabetes, and Obesity 201118 359-370.

8 Marx SJ, Attie MF, Stock JL, Spiegel AM \& Levine MA. Maximal urine-concentrating ability: familial hypocalciuric hypercalcemia versus typical primary hyperparathyroidism. Journal of Clinical Endocrinology and Metabolism 198152 736-740. (doi:10.1210/ jcem-52-4-736)

9 Attie MF, Gill JR Jr, Stock JL, Spiegel AM, Downs RW Jr, Levine MA \& Marx SJ. Urinary calcium excretion in familial hypocalciuric hypercalcemia. Persistence of relative hypocalciuria after induction of hypoparathyroidism. Journal of Clinical Investigation 198372 667-676. (doi:10.1172/JCI111016)

10 Nesbit MA, Hannan FM, Howles SA, Reed AA, Cranston T, Thakker CE, Gregory L, Rimmer AJ, Rust N, Graham U et al. Mutations in AP2S1 cause familial hypocalciuric hypercalcemia type 3. Nature Genetics 201345 93-97. (doi:10.1038/ng.2492)

11 Pallais JC, Kifor O, Chen YB, Slovik D \& Brown EM. Acquired hypocalciuric hypercalcemia due to autoantibodies against the calcium-sensing receptor. New England Journal of Medicine 2004 351 362-369. (doi:10.1056/NEJMoa040008)

12 Kifor O, Moore FD Jr, Delaney M, Garber J, Hendy GN, Butters R, Gao P, Cantor TL, Kifor I, Brown EM et al. A syndrome of hypocalciuric hypercalcemia caused by autoantibodies directed at the calcium-sensing receptor. Journal of Clinical Endocrinology and Metabolism 200388 60-72. (doi:10. 1210/jc.2002-020249)

13 Silverberg SJ, Lewiecki EM, Mosekilde L, Peacock M \& Rubin MR. Presentation of asymptomatic primary hyperparathyroidism: proceedings of the third international workshop. Journal of Clinical Endocrinology and Metabolism 200994 351-365. (doi:10.1210/ jc.2008-1760)
14 Rubin MR, Maurer MS, McMahon DJ, Bilezikian JP \& Silverberg SJ. Arterial stiffness in mild primary hyperparathyroidism. Journal of Clinical Endocrinology and Metabolism 200590 3326-3330. (doi:10.1210/jc.2004-1400)

15 Sheldon DG, Lee FT, Neil NJ \& Ryan JA Jr. Surgical treatment of hyperparathyroidism improves health-related quality of life. Archives of Surgery 2002137 1022-1026 (discussion 10261028). (doi:10.1001/archsurg.137.9.1022)

16 Fraser WD. Hyperparathyroidism. Lancet 2009374 145-158. (doi:10.1016/S0140-6736(09)60507-9)

17 Amstrup AK, Rejnmark L \& Mosekilde L. Patients with surgically cured primary hyperparathyroidism have a reduced quality of life compared with population-based healthy sex-, age-, and seasonmatched controls. European Journal of Endocrinology 2011165 753-760. (doi:10.1530/EJE-11-0301)

18 Deutch SR, Jensen MB, Christiansen PM \& Hessov I. Muscular performance and fatigue in primary hyperparathyroidism. World Journal of Surgery $2000 \quad \mathbf{2 4}$ 102-107. (doi:10.1007/s002689910019)

19 Ljunghall S, Akerstrom G, Johansson G, Olsson Y \& Stålberg E. Neuromuscular involvement in primary hyperparathyroidism. Journal of Neurology 1984231 263-265. (doi:10.1007/BF00 313663)

20 Moosgaard B, Christensen SE, Vestergaard P, Heickendorff L, Christiansen P \& Mosekilde L. Vitamin D metabolites and skeletal consequences in primary hyperparathyroidism. Clinical Endocrinology 200868 707-715. (doi:10.1111/j.1365-2265.2007. 03109.x)

21 Christensen SE, Nissen PH, Vestergaard P, Heickendorff L, Rejnmark L, Brixen K \& Mosekilde L. Plasma 25-hydroxyvitamin D, 1,25-dihydroxyvitamin D, and parathyroid hormone in familial hypocalciuric hypercalcemia and primary hyperparathyroidism. European Journal of Endocrinology $2008 \quad \mathbf{1 5 9} \quad 719-727$. (doi:10.1530/EJE-08-0440)

22 Schmitt CP, Odenwald T \& Ritz E. Calcium, calcium regulatory hormones, and calcimimetics: impact on cardiovascular mortality. Journal of the American Society of Nephrology 200617 S78-S80. (doi:10.1681/ASN.2005121338)

23 Baczynski R, Massry SG, Magott M, el-Belbessi S, Kohan R \& Brautbar N. Effect of parathyroid hormone on energy metabolism of skeletal muscle. Kidney International $1985 \mathbf{2 8}$ 722-727. (doi:10.1038/ki.1985.190)

24 Law WM Jr \& Heath H III. Familial benign hypercalcemia (hypocalciuric hypercalcemia). Clinical and pathogenetic studies in 21 families. Annals of Internal Medicine 1985102 511-519. (doi:10.7326/0003-4819-102-4-511)

25 Foley TP Jr, Harrison HC, Arnaud CD \& Harrison HE. Familial benign hypercalcemia. Journal of Pediatrics 197281 1060-1067. (doi:10.1016/S0022-3476(72)80232-4)

26 Harding B, Curley AJ, Hannan FM, Christie PT, Bowl MR, Turner JJ, Barber M, Gillham-Nasenya I, Hampson G, Spector TD et al. Functional characterization of calcium sensing receptor polymorphisms and absence of association with indices of calcium homeostasis and bone mineral density. Clinical Endocrinology 200665 598-605. (doi:10.1111/j.1365-2265. 2006.02634.x)

27 Maunsell Z, Wright DJ \& Rainbow SJ. Routine isotope-dilution liquid chromatography-tandem mass spectrometry assay for simultaneous measurement of the 25-hydroxy metabolites of vitamins D2 and D3. Clinical Chemistry 200551 1683-1690. (doi:10.1373/clinchem.2005.052936)

28 Hojskov CS, Heickendorff L \& Moller HJ. High-throughput liquid-liquid extraction and LCMSMS assay for determination of circulating $25(\mathrm{OH})$ vitamin D3 and D2 in the routine clinical laboratory. Clinica Chimica Acta $2010 \mathbf{4 1 1} 114-116$. (doi:10.1016/j.cca.2009.10.010)

29 Nissen PH, Christensen SE, Ladefoged SA, Brixen K, Heickendorff L \& Mosekilde L. Identification of rare and frequent variants of the CASR gene by high-resolution melting. Clinica Chimica Acta 2012 413 605-611. (doi:10.1016/j.cca.2011.12.004) 
30 den Dunnen JT \& Antonarakis SE. Nomenclature for the description of human sequence variations. Human Genetics 2001 109 121-124. (doi:10.1007/s004390100505)

31 Tiainen K, Sipila S, Kauppinen M, Kaprio J \& Rantanen T. Genetic and environmental effects on isometric muscle strength and leg extensor power followed up for three years among older female twins. Journal of Applied Physiology $2009 \mathbf{1 0 6}$ 1604-1610. (doi:10.1152/japplphysiol.91056.2008)

32 Era P, Sainio P, Koskinen S, Haavisto P, Vaara M \& Aromaa A. Postural balance in a random sample of 7,979 subjects aged 30 years and over. Gerontology 200652 204-213. (doi:10.1159/ 000093652 )

33 Ostchega Y, Harris TB, Hirsch R, Parsons VL, Kington R \& Katzoff M. Reliability and prevalence of physical performance examination assessing mobility and balance in older persons in the US: data from the Third National Health and Nutrition Examination Survey. Journal of the American Geriatrics Society 200048 1136-1141.

34 Bohannon RW. Reference values for the timed up and go test: a descriptive meta-analysis. Journal of Geriatric Physical Therapy 200629 64-68. (doi:10.1519/00139143-20060800000004)

35 Csuka M \& McCarty DJ. Simple method for measurement of lower extremity muscle strength. American Journal of Medicine $1985 \mathbf{7 8}$ 77-81. (doi:10.1016/0002-9343(85)90465-6)

36 Aadahl M \& Jorgensen T. Validation of a new self-report instrument for measuring physical activity. Medicine and Science in Sports and Exercise 200335 1196-1202. (doi:10.1249/01. MSS.0000074446.02192.14)

37 Caillard C, Sebag F, Mathonnet M, Gibelin H, Brunaud L, Loudot C, Kraimps JL, Hamy A, Bresler L \& Charbonnel B. Prospective evaluation of quality of life (SF-36v2) and nonspecific symptoms before and after cure of primary hyperparathyroidism (1-year follow-up). Surgery 2007141 153-159 (discussion 159-160). (doi:10.1016/j.surg.2006.12.004)
38 Bech P, Olsen LR, Kjoller M \& Rasmussen NK. Measuring wellbeing rather than the absence of distress symptoms: a comparison of the SF-36 Mental Health subscale and the WHO-Five Well-Being Scale. International Journal of Methods in Psychiatric Research 2003 12 85-91. (doi:10.1002/mpr.145)

39 Hermann AP, Thomsen J, Vestergaard P, Mosekilde L \& Charles P. Assessment of calcium intake. A quick method compared to a 7 days food diary. Calcified Tissue International 199964 (suppl 1) S82.

40 Egbuna OI \& Brown EM. Hypercalcaemic and hypocalcaemic conditions due to calcium-sensing receptor mutations. Best Practice \& Research. Clinical Rheumatology 200822 129-148. (doi:10.1016/j.berh.2007.11.006)

41 Smock SL, Vogt GA, Castleberry TA, Lu B \& Owen TA. Molecular cloning and functional characterization of the canine parathyroid hormone/parathyroid hormone related peptide receptor (PTH1). Molecular Biology Reports 200128 235-243. (doi:10.1023/ A:1015716726452)

42 Ceglia L. Vitamin D and skeletal muscle tissue and function. Molecular Aspects of Medicine 200829 407-414. (doi:10.1016/j. mam.2008.07.002)

43 Joborn C, Rastad J, Stalberg E, Akerström G \& Ljunghall S. Muscle function in patients with primary hyperparathyroidism. Muscle $\mathcal{E}$ Nerve 198912 87-94. (doi:10.1002/mus.880120202)

44 Amstrup AK, Rejnmark L, Vestergaard P, Sikjaer T, Rolighed L, Heickendorff L \& Mosekilde L. Vitamin D status, physical performance and body mass in patients surgically cured for primary hyperparathyroidism compared with healthy controls - a cross-sectional study. Clinical Endocrinology 201174 130-136. (doi:10.1111/j.1365-2265.2010.03906.x)

Received 25 March 2013

Revised version received 8 June 2013

Accepted 13 June 2013 